OPEN ACCESS

Edited by:

Mitsuo Tagaya,

Tokyo University of Pharmacy and Life

Sciences, Japan

Reviewed by:

Mitsunori Fukuda,

Tohoku University, Japan

Cecilia Bucci,

University of Salento, Italy

Guangpu Li,

University of Oklahoma Health

Sciences Center, United States

*Correspondence:

Hangyu Li

sj_li_hangyu@sina.com

tThese authors have contributed equally to this work

Specialty section:

This article was submitted to Membrane Traffic

a section of the journal

Frontiers in Cell and Developmental

Biology

Received: 31 December 2020 Accepted: 10 May 2021

Published: 01 June 2021

Citation:

Jin $H$, Tang $Y$, Yang $L$, Peng $X$, Li B, Fan Q, Wei S, Yang S, Li X, Wu B, Huang M, Tang S, Liu J and

Li H (2021) Rab GTPases: Central Coordinators of Membrane Trafficking

in Cancer.

Front. Cell Dev. Biol. 9:648384. doi: 10.3389/fcell.2021.648384

\section{Rab GTPases: Central Coordinators of Membrane Trafficking in Cancer}

\author{
Hongyuan Jin', Yuanxin Tang ${ }^{\dagger}$ Liang Yang, Xueqiang Peng, Bowen Li, Qin Fan, \\ Shibo Wei, Shuo Yang, Xinyu Li, Bo Wu, Mingyao Huang, Shilei Tang, Jingang Liu and \\ Hangyu $\mathrm{Li}^{*}$
}

Department of General Surgery, The Fourth Affiliated Hospital of China Medical University, Shenyang, China

Tumor progression involves invasion, migration, metabolism, autophagy, exosome secretion, and drug resistance. Cargos transported by membrane vesicle trafficking underlie all of these processes. Rab GTPases, which, through coordinated and dynamic intracellular membrane trafficking alongside cytoskeletal pathways, determine the maintenance of homeostasis and a series of cellular functions. The mechanism of vesicle movement regulated by Rab GTPases plays essential roles in cancers. Therefore, targeting Rab GTPases to adjust membrane trafficking has the potential to become a novel way to adjust cancer treatment. In this review, we describe the characteristics of Rab GTPases; in particular, we discuss the role of their activation in the regulation of membrane transport and provide examples of Rab GTPases regulating membrane transport in tumor progression. Finally, we discuss the clinical implications and the potential as a cancer therapeutic target of Rab GTPases.

Keywords: Rab GTPase, membrane trafficking, cancer biology, GEF, GDP

\section{KEY POINTS:}

1. There are $66 \mathrm{Rab}$ GTPases associated with vesicular transport in the human genome.

2. The GEFs and GDPs make Rab GTPases act as molecular switches.

3. Based on membrane trafficking function, Rab GTPases are important to cancer progression.

4. Targeting Rab GTPases provides possibilities for cancer treatment strategies.

\section{INTRODUCTION}

Although many studies have strongly supported the notion that the dysregulation of invasion, migration, metabolism, autophagy, exosome secretion and drug resistance mediate cancer progression, few studies have focused on intracellular membrane trafficking, which regulates these processes (Prasad et al., 2016). Membrane trafficking enables the distribution of cellular proteins and the secretion of extracellular vesicles (Kajiho et al., 2018). Notably, the transport of membrane along the cytoskeleton regulates various biological functions in the cell. Membrane trafficking in cancer is crucial to these processes, in which membrane dynamics mediate their physical requirements (Stenmark, 2009). Indeed, variations in the presentation and degradation of important membrane proteins and imbalance in dynamic vesicle trafficking processes are known to be critical in tumor progression (Cho et al., 2018; Drizyte-Miller et al., 2020; Yousaf and Ali, 2020). Thus, membrane trafficking is a focal point for targeting cancer. Membrane trafficking can "drive" 
cancer progression and enable invasion, migration, metabolism, autophagy, exosome secretion and drug resistance.

Rab GTPases are highly conserved regulators of vesicular transport, and 66 members of this family in the human genome have been described (Li and Marlin, 2015). They switch between an active and inactive state, which is modulated by guanine nucleotide exchange factor (GEF) and GTPase activating protein (GAP), and function via downstream molecules, such as coat proteins and motor proteins, to trigger downstream membrane trafficking (Lamber et al., 2019). Each Rab GTPase is localized to a different membrane compartment, where it controls the specificity and direction of membrane transport (Stenmark, 2009). Rab GTPases regulate different trafficking routes and perform specific tasks in a series of membrane trafficking steps (Minamino and Ueda, 2019). Indeed, Rab GTPases ensure that cargos are transported to the correct target. Through transient interactions with downstream molecules, they control the formation of membrane buds, vesicular transport along the cytoskeleton, and membrane fusion to the target compartment (Cernochova et al., 2016; Burk and Pasterkamp, 2019).

As cancer cells live in changing microenvironments, they need a class of checkpoints that regulate the balance among endocytosis, recycling, degradation and exocytosis to face external stresses (Yang T. et al., 2020). Rab GTPases play a specific and predominant role in vesicle trafficking (Homma et al., 2020). Research has traditionally been mainly focused on regulation of the transcription or translation of Rab GTPases. Changes in Rab GTPase expression are associated with invasion, migration, metabolism, autophagy, exosome secretion and drug resistance in cancer (Table 1). A number of these changes are caused by changes in vesicular transport pathways, which influences cargo delivery to the cellular membrane and cargo endocytosis, recycling, degradation in lysosomes and exocytosis (Lamber et al., 2019). The checkpoint between recycling and degradation can significantly affect the cell biological function (Cullis et al., 2002; Ceresa and Bahr, 2006). Increases in endocytosis and endocytosed proteins transported to the lysosomes can decrease cell surface proteins (Drizyte-Miller et al., 2020). Indeed, error in the delivery of proteins to the cell surface or lysosomes causes abnormalities in polarity and membrane protein function, which can significantly affect cell invasion, migration and drug resistance. In addition, the overexpression or knockdown of Rab GTPases to reduce exosome transmission affected cancer progression (Hendrix and De Wever, 2013; Li et al., 2013; Huang and Feng, 2017; Chen et al., 2018; Guo et al., 2019). In addition, changes in internal trafficking decisions, including decisions to recycle and degrade through regulating ubiquitinylation and autophagy, can regulate receptor signaling and related protein function (Dong et al., 2019; Drizyte-Miller et al., 2020). In conclusion, the regulation of vesicle trafficking by Rab GTPases can affect receptor recycling and trafficking, which can affect tumor invasion, migration, metabolism, autophagy, exosome secretion and drug resistance. These roles and the subcellular localization of b GTPases are briefly summarized in Figure $\mathbf{1}$. This review seeks to highlight the potential contributions of Rab GTPase-mediated membrane trafficking to tumor progression, the clinical implications of Rab GTPases and the therapeutic potential of targeting Rab GTPases.

Active Rab GTPases locate in specific membrane compartments and function in cancer by membrane trafficking, according to Table 1. In the early endosome, Rab5 and Rab21 regulate the endocytosis of integrins and ABCG2 in cell surface. In the recycling endosome, Rab4, Rab8, Rab10, Rab11b, Rab13, Rab25, and Rab35 recycle endosomal integrins, MMPs, EGFR, and TNFRSF10B to the cell surface. In the late endosome, Rab2a control the endocytic recycling of MMT1-MMP; Rab7a affects resistance by increasing the secretion of extracellular vesicle. In the LDs, Rab7 and Rab10 induces the selective autophagy of LDs (lipophagy). In the autophagosome, Rab7 and Rab10 regulate lipophagy; Rabla and Rab10 control the formation of autophagosome; Rab2 and Rab7 regulate the maturation of autophagosome. In the lysosome, Rab2a functions in autophagosome clearance; Rab7 regulate lipophagy; Rab32 regulate the transport of mTOR signaling protein into lysosome. In Golgi apparatus, Rab1b regulate the secretion of MMP1 from Golgi apparatus; Rab2a control the transport of E-cadherin to the Golgi apparatus. In the secretory vesicle, Rab27, Rab37 and Rab40 control the exocytosis of MMP1, TIMP1, or TIMP2; Rab8 increases the secretion of TMP. In the MVB, Rab11, Rab27, and Rab35 control exosome biogenesis and secretion process.

\section{RAB GTPase FUNCTION IN MEMBRANE TRAFFICKING}

Many studies have indicated that different Rab GTPases function closely in arranging membrane transport (Stenmark, 2009). These classes of Rab GTPases can define distinct types of membranes and regulate membrane tethering, movement and fate. Rab GTPases are present in an active or inactive state. Their nucleotide-dependent conformational transformation makes Rab GTPases act as molecular switches. The guanine nucleotidebound state of Rab GTPases is regulated by GAPs or GEFs (Lamber et al., 2019). Rab GTPase contains two switch regions affected by GTP/GDP binding state (Goud et al., 2018). Through specific binding to the two switch regions, GAPs and GEFs control the GTP/GDP cycle (Figure 2). Every GTP/GDP cycle represents an opportunity to adjust the transport direction: to recruit a tether protein or a motor protein and promote traffic, or to adjust downstream proteins from actin filaments to microtubules, or to hand off the regulation of trafficking between Rab-dependent regulators (Malia et al., 2018; Baba et al., 2019; Dolce et al., 2020).

Hence, GAP/GEF determine the quantities of active Rab GTPases. Impairment of GAPs or overexpression of GEFs can cause an increase in active Rab GTPases, influencing the recruitment of downstream effectors regulated by active Rab GTPases, then may regulate cancer progression (Novick, 2016). For example, the eco tropic viral integration site 5 (EVI5), which belongs to a small subfamily of Tre-2/Bub2/Cdc16 (TBC) domain-containing proteins, is an oncogene that regulates the proliferation and metastasis in lung cancer (Cai et al., 2020). And there has been a promising prognosis predicting model for 
TABLE 1 | The role of vesicle trafficking medicated by Rab GTPases in cancer research.

\begin{tabular}{|c|c|c|c|c|}
\hline Functions & Rab GTPases & Regulatory factors & Cancer research & References \\
\hline \multirow[t]{14}{*}{ Invasion } & Rab1b & MMP1 & Breast/melanoma/colon cancer & Pellinen et al., 2006 \\
\hline & Rab2a & MT1-MMP & Breast cancer & Yuan and Wei, 2021 \\
\hline & Rab4a & Procathepsin L & Melanoma & Halberg et al., 2016 \\
\hline & Rab4/Rab5 & MT1-MMP & Breast cancer & Howe et al., 2020 \\
\hline & Rab7 & MT1-MMP & Colon cancer & Kajiho et al., 2016 \\
\hline & Rab8 & MT1-MMP & Breast cancer & Jeong et al., 2019 \\
\hline & Rab11 & Integrin $\alpha 6 \beta 4$ & Breast cancer & Nam et al., 2010 \\
\hline & Rab25 & Integrin $\alpha 5 \beta 1$ and $\beta 1$ & Breast cancer & Jeong et al., 2018 \\
\hline & Rab27a & MMP9 & Breast cancer & Bravo-Cordero et al., 2007 \\
\hline & & Cytokines & Colon cancer & Li et al., 2013 \\
\hline & Rab27b & MMP2 & Breast cancer & Yoon et al., 2005 \\
\hline & Rab37 & TIMP1 & Non-small-cell lung cancer & $\begin{array}{l}\text { Argenzio et al., 2014; } \\
\text { Sahgal et al., } 2019\end{array}$ \\
\hline & & TIMP2 & Nasopharyngeal carcinoma & $\begin{array}{l}\text { Argenzio et al., 2014; } \\
\text { Sahgal et al., } 2019\end{array}$ \\
\hline & Rab40 & MMP2/9 & Breast cancer & Wang et al., 2019 \\
\hline \multirow[t]{11}{*}{ Migration } & Rab5 & Integrin $\beta 1$ & Breast/prostate cancer & Caswell et al., 2007 \\
\hline & Rab5a & Integrin $\beta 1$ & Pancreatic cancer & Jacob et al., 2013 \\
\hline & Rab10 & Integrin $\beta 1$ & Cervical cancer & Bobrie et al., 2012 \\
\hline & Rab11b & Integrin $\beta 1$ & Breast cancer & Li et al., 2018 \\
\hline & Rab13 & Integrin $\beta 1$ & Cervical cancer & Bobrie et al., 2012 \\
\hline & Rab21 & Integrin $\beta 1$ & Breast/prostate cancer & Caswell et al., 2007 \\
\hline & Rab25 & Integrin $\alpha 1 / \beta 4 / \beta 6$ & Skin squamous carcinoma & Wang et al., 2018 \\
\hline & & Integrin $\beta 1$ & Non-small-cell lung cancer & $\begin{array}{l}\text { Steffan et al., 2014; } \\
\text { Alonso-Curbelo et al., } 2014\end{array}$ \\
\hline & & Integrin $\beta 1$ & Ovarian cancer & $\begin{array}{l}\text { Steffan et al., 2014; } \\
\text { Alonso-Curbelo et al., } 2014\end{array}$ \\
\hline & & Integrin $\beta 1$ & Colon cancer & Barbarin and Frade, 2011 \\
\hline & Rab35 & Integrin $\beta 1$ & Breast/ cervical cancer & Hendrix et al., 2010 \\
\hline Growth Factor Driven & Rab5 & EGFR & Breast cancer & Stallaert et al., 2018 \\
\hline \multirow{5}{*}{$\begin{array}{l}\text { Signaling of Migration } \\
\text { and Invasion }\end{array}$} & Rab7 & HGF & Colon cancer & Kajiho et al., 2016 \\
\hline & Rab10 & HGF & Hepatocellular carcinoma & Wang W. et al., 2017 \\
\hline & Rab11 & HGF & Gastric cancer & Dong et al., 2016 \\
\hline & Rab11a & EGFR & Breast cancer & Yamori et al., 1981 \\
\hline & Rab31 & HGF & Colon Cancer & Yang Y. et al., 2020 \\
\hline \multirow[t]{2}{*}{ Metabolism } & Rab32 & mTOR & Hepatocellular carcinoma/cervical cancer & Drizyte-Miller et al., 2020 \\
\hline & Rab25 & GLUT1 & Breast/ ovarian cancer & Cheng et al., 2012 \\
\hline \multirow[t]{7}{*}{ Autophagy } & Rab1a & Autophagosome & Neuroblastoma & Song et al., 2018 \\
\hline & Rab2/Rab7 & Autolysosome & Breast cancer & Lorincz et al., 2017 \\
\hline & Rab2a & Autophagosome & Breast cancer & Ding et al., 2019 \\
\hline & Rab10 & LD & Hepatocellular carcinoma & $\begin{array}{l}\text { Li et al., 2016; Li et al., } \\
\text { 2020b }\end{array}$ \\
\hline & Rab7 & LD & Hepatocellular carcinoma & Cho et al., 2018 \\
\hline & Rab25 & Autophagosome & Ovarian cancer & Liu et al., 2012 \\
\hline & Rab2/Rab7 & Autophagosome & Renal carcinoma & Tringali et al., 2012 \\
\hline \multirow[t]{6}{*}{ Exosome } & Rab11 & Exosome secretion & Leukemia & Savina et al., 2002 \\
\hline & & Exosome secretion & Leukemia & Savina et al., 2005 \\
\hline & & Exosomal TMPRSS2 & Breast cancer & Chi et al., 2020 \\
\hline & Rab27 & Exosomal miR-23b & Bladder carcinoma & Ostenfeld et al., 2014 \\
\hline & Rab27a & Exosome secretion (size of MVB) & Ovarian cancer & Ostrowski et al., 2010 \\
\hline & & Exosome & Melanoma & $\begin{array}{l}\text { Hendrix and De Wever, } \\
\text { 2013; Chen et al., 2018; } \\
\text { Guo et al., } 2019\end{array}$ \\
\hline
\end{tabular}


TABLE 1 | Continued

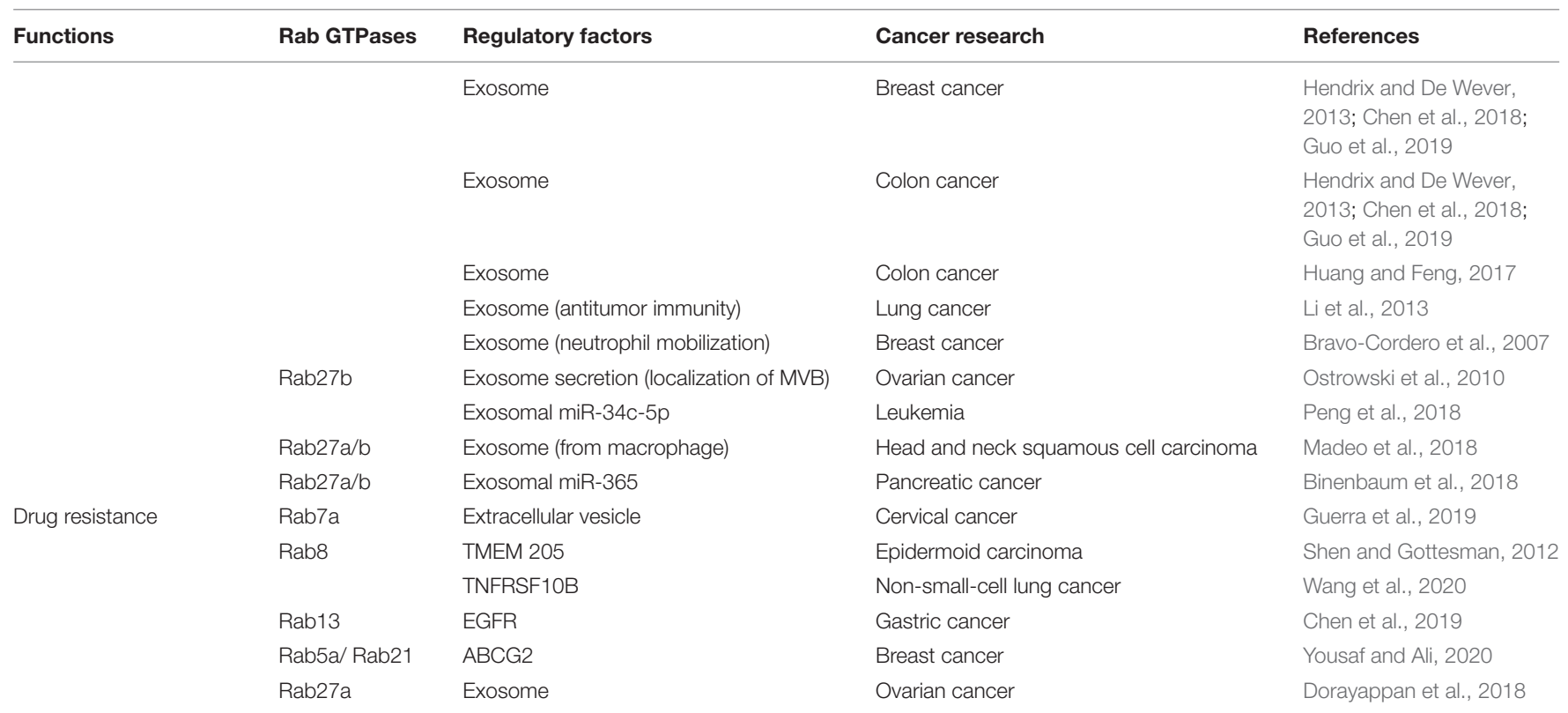

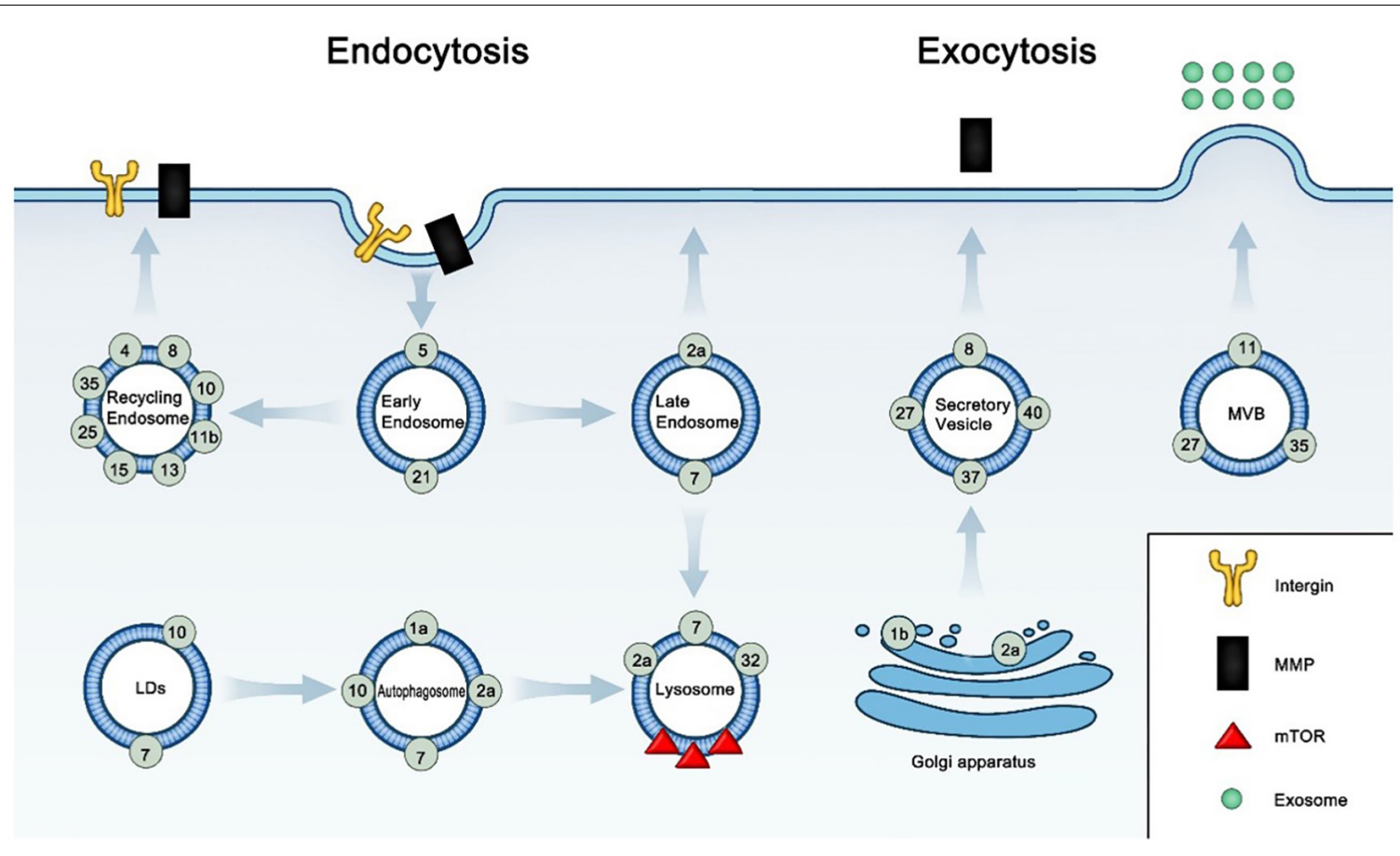

FIGURE 1 | Subcellular localization and relative function of Rab GTPases in cancer.

melanoma based on TBC family protein (Tang D. et al., 2020). Furthermore, Rab8 and Rabin8 (the GEF of Rab8) promote tumor formation (Choi et al., 2020).

In addition to GAPs and GEFs, Rab GDP dissociation inhibitors (GDIs) and Rab escort proteins (REPs) also functions in the adjustment of the Rab GTPases activity (Stenmark, 2009; Müller and Goody, 2018). GDIs were initially identified as factors preventing the release of GDP from the Rab GTPases and stabilizing the inactive state of Rab GTPases. And GDIs and GEFs also function as chaperones of Rab GTPases in the cytoplasm. RabIF, one of the GEFs, could stabilize the protein expression of Rab10 (Gulbranson et al., 2017). And two GDIs (GDI1 and GDI2) could regulate the geranylgeranylation of Rab GTPases and thus regulate their delivery and recycle. REPs also modulate the geranylgeranylation of Rab GTPases and affect their targeting in the membrane trafficking. 


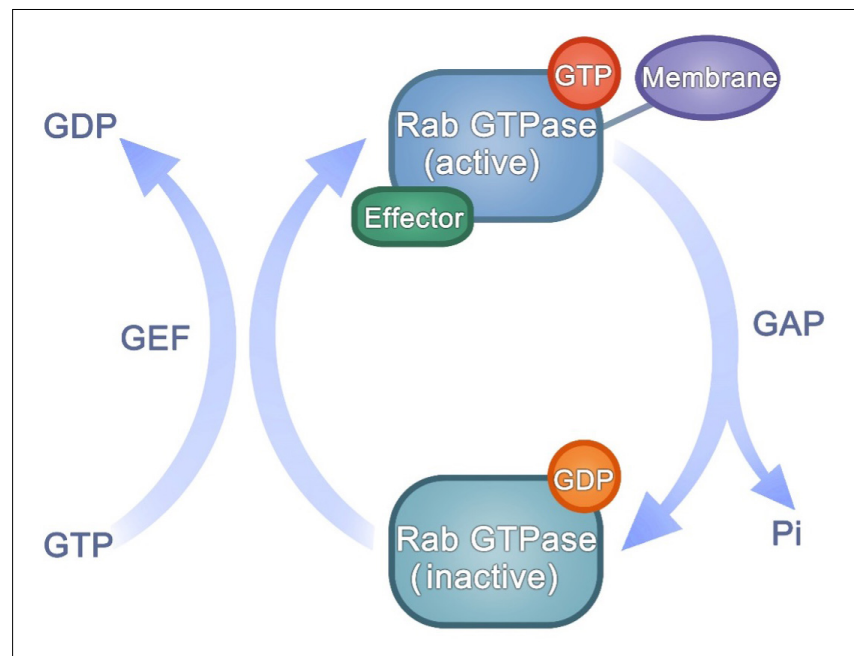

FIGURE 2 | The activation of Rab GTPases.

Some studies indicate that one Rab GTPase can interact with the GEFs or GAPs specific for other Rab GTPases, a critical discovery for their ordered activation in the membrane transport process (Tang L. et al., 2020). After activation, Rab GTPases can interact with multiple effectors in time and space to selectively regulate cargos into vesicles, exert vesicle movement along actin and microtubule cables, and tether vesicles for membrane fusion. For example, Rab GTPase adaptor proteins and lipid kinases and phosphatases assist Rab GTPases in cargo selection and membrane remodeling (Malia et al., 2018; Baba et al., 2019). In addition, Rab GTPases bind motor proteins to regulate vesicular transport along the cytoskeleton and function with tethering proteins in membrane fused with the target compartment (Dolce et al., 2020).

Rab GTPases switch between active and inactive conformations in a GTP-dependent mode. GEF catalyzes GDP-bound to GTP-bound, while GAP promotes the opposite process. The GTP/GDP cycle affects the state of Rab GTPases, and the activated Rab GTPases can bind to downstream effectors and function in regulating membrane trafficking.

\section{RAB GTPases AND CANCER PROGRESSION}

\section{Migration and Invasion}

Tumor metastasis is inseparable from abnormal cell invasion, proliferation, migration and angiogenesis, among which cell migration and invasion are the most important markers (Gkretsi and Stylianopoulos, 2018). Cell migration and invasion require a class of cell processes, including the intracellular vesicular transport of cell adhesion receptor molecules (such as integrins, cadherin-catenin) and proteases (Castro-Castro et al., 2016; LaFlamme et al., 2018). It has also been determined that ligandgrowth factor receptor interactions through membrane transport pathways are associated with two important stages of cancer metastasis: cell invasion and migration. There is no doubt that vesicle trafficking medicated by Rab GTPases plays an important role in these processes.

Knowledge of the Rab GTPases functions in vesicular transport is crucial to understand the mechanisms of migration and invasion. Specifically, cell migration and invasion require the redistribution of adhesive components and the directional delivery of matrix-degrading enzymes.

\section{Migration}

In the former, integrins trafficked to the cell surface regulate the formation of filopodia and actin-matrix interactions, which can significantly affect cell adhesion and migration. Rab5 and Rab21 regulate the endosomal trafficking of integrin $\beta 1$ and their overexpression increases the ability of cell migration and adhesion (Pellinen et al., 2006). Rab5a also promotes the formation of filopodia that promote migration in pancreatic cancer cells by activating integrin $\beta 1$ (Yuan and Wei, 2021). The Rab11 protein family (Rab11b and Rab25) have played a key role in cancer cell migration by regulating integrin recirculation at the migration front. Regulation of integrin $\beta 1$ surface expression by Rab11b plays a crucial role in cell adhesion, activating Erk signaling and promoting the adaptation and growth of breast cancer brain metastases (Howe et al., 2020). Rab25 can act as a tumor suppressor or tumor promoter in different tumors. Rab25 plays a tumor suppressive role in colorectal cancer and cutaneous squamous cell carcinoma. Rab25 deficiency induced the impairment of integrin $\beta 1, \beta 4$, and $\alpha 6$ recycling, causing the improper expression of integrins in skin squamous cell carcinoma (Jeong et al., 2019). Besides, loss of Rab25 prominent reductions in integrin $\beta 1$ and promotes integrin $\beta 1$ away from the lateral membranes in colon cancer (Nam et al., 2010). By contrast, Rab25 promotes integrin $\beta 1$ trafficking to the cytoplasmic membrane in non-small-cell lung cancer and ovarian cancer and acts as a tumor promoter (Jeong et al., 2018; Wang et al., 2019). In ovarian cancer, Rab25-medicated integrin $\beta 1$ activates EGFR/VEGF/Snail axis and then promote cell invasion. And in non-small-cell lung cancer, Rab25-medicated integrin $\beta 1$ activates $\mathrm{AKT} / \beta$-catenin pathway. Integrin recycling is also mediated by Rab10 and Rab13. Rab10 and Rab13 interact with Golgi-localized gamma ear-containing Arf-binding protein 2 and facilitate the recycling of active integrin $\beta 1$ to the cell surface in cervical cancer (Sahgal et al., 2019). Another Rab GTPase controlling the recycling of integrin is Rab35. Rab35 can increase the expression of integrin $\beta 1$ in cervical and breast cancer and promote cell migration (Argenzio et al., 2014).

\section{Invasion}

In the latter, tumor cells secrete a variety of proteases, such as MMP, that help cells break through the basement membrane and ECM. Some Rab GTPases have been described in the context of MMP secretion or activation vesicular transport regulates the delivery of MMPs and other proteins to change the extracellular matrix and thereby affect cell invasion. MT1-MMP (Membranetype 1-matrix metalloproteinase) and other MMPs are essential for matrix remodeling and invasion. For example, Rab1b can regulate metastasis by increasing the secretion of MMP1 (Halberg et al., 2016). Rab2a regulates MT1-MMP endocytic recycling 
and the transport of E-cadherin to the Golgi to promote cell invasion in breast cancer (Kajiho et al., 2016). Rab5/Rab4 promotes invasion by MT1-MMP in invasive breast cancer (Frittoli et al., 2014). Rab8 controls the exocytosis of MT1-MMP in breast cancer (Bravo-Cordero et al., 2007). Rab11 promotes the trafficking of the integrin $\alpha 6 \beta 4$ under hypoxic conditions, which leads to increased cell invasion of breast cancer cells (Yoon et al., 2005). Rab25 promote cell invasion into the 3D ECM by integrin $\alpha 5 \beta 1$ and $\beta 1$ (Caswell et al., 2007). Additionally, Rab40b functions as a regulator in the transport of MMP2/9 during invadopodia formation in breast cancer (Jacob et al., 2013).

Indeed, Rab GTPases could also affect MMP inhibitors to suppress tumor invasion. For example, Rab37 controls the exocytosis of TIMP1 to inhibit inactivated MMP9 and thereby suppresses lung cancer metastasis and controls the exocytosis of TIMP2 to inhibit inactivated MMP2 in nasopharyngeal carcinoma (Li et al., 2018; Wang et al., 2018). Another protease important for the cell invasion is procathepsin L, whose secretion is regulated by Rab4a (Barbarin and Frade, 2011).

In addition, some Rab GTPases play a dual role in the regulation of cell invasion. For example, Rab7 knockdown is associated with MT1-MMP secretion and promotion of cell migration and invasion in colorectal cancer cells (Steffan et al., 2014). On the other hand, high Rab7 expression is an indicator of a higher risk of metastasis in early melanoma patient (AlonsoCurbelo et al., 2014). Another example is Rab27. Rab27a controls the secretion of MMP9 that degrades extracellular matrix proteins to promote invasion and migration (Bobrie et al., 2012). In the ER + breast cancer, Rab27b activates MMP2 secretion and stimulates breast cancer cell invasion (Hendrix et al., 2010). By contrast, Rab27a overexpressed cell-derived exosomes has been shown to suppress tumor formation in vivo in a mouse model, which is related to cytokines (Li et al., 2013). The opposite effect of Rab7 and Rab27 may be attributable to cancer type, stage and specific growth factor stimulation.

\section{Growth Factor Driven Signaling of Migration and Invasion}

The involvement of growth factor driven signaling is also essential for tumor cell invasion and migration. Rab GTPases regulate early endocytic transport of several growth factors that promote tumor cell invasion and metastasis, including epithelial growth factor (EGFR) and hepatocyte growth factor (HGF) (Porther and Barbieri, 2015). The activation of EGFR signaling and HGF signaling can activate mitogen-activated protein kinases (MAPK) signaling pathway that promote the transcription and secretion of metalloproteinases MMP2 and MMP9, actin aggregation and integrin distribution, and thus promote migration and invasion (Porther and Barbieri, 2015). In the triple-negative breast cancer, Rab5 regulate EGFR vesicular recycling to promote migration (Stallaert et al., 2018). Interestingly, Rab1la regulates EGFR circulation and promotes proliferation, but inhibits the movement in breast cancer (Yamori et al., 1981). Rab7 shRNA expressing cells were found to be more invasive, and increased invasiveness was accompanied by high activation level of HGF signaling (Steffan et al., 2014). Rab10 silencing inhibits the HGF pathway, while
Rab10 overexpression indicates poor prognosis of hepatocellular carcinoma (Wang W. et al., 2017). High expression of Rab11 was closely correlated with nodal metastasis in gastric cancer tissues (Dong et al., 2016). The expression level of Rab11 was significantly increased and associated with HGF pathway. In colon cancer, increased Rab31 expression may promote tumor progression by regulating HGF secretion in the tumor stroma (Yang Y. et al., 2020). These studies suggest that vesicle trafficking modulated by Rab GTPases is involved in multiple cell invasion and migration pathways.

\section{Metabolism}

Vesicular transport pathway and metabolic signaling pathway both involve moving substances (or signals) around the cell surface and within the cell (Chua and Tang, 2015). There is a chain of evidence to suggest that the transport and metabolic signaling pathways intersect-vesicular transport can affect the regulation of metabolic signals (Cheng et al., 2012; Wu et al., 2014; Drizyte-Miller et al., 2020). Considering Rab GTPases modulate the specificity and direction of vesicular transport, there are no doubt that they can decide the points at which vesicular transport and metabolism interact.

Rab GTPases mainly regulate the trafficking of GLUT (glucose transporter) and the formation of lipid droplet (LD) in glucose and lipid metabolism of cancer cells. GLUT1 is responsible for maintaining the basic uptake of glucose for the basic respiratory process in all cells, and responds to low levels of glucose, which increase in the cell membrane (Yang et al., 2021). Rab25 increases glycogen reserve and ATP levels in ovarian cancer cells through regulating the transport of GLUT1 to the cell surface and thus enhancing glucose uptake (Cheng et al., 2012). Although glucose metabolism is an important part of cell function, another critical aspect of cell metabolism involves lipids. A particularly salient aspect of metabolic reprogramming in tumor cells involves lipid storage and mobilization. LDs function in intracellular lipid storage, maintaining the cellular level of free lipids and energy homeostasis (Jackson, 2019). And Rab8a is reported to control lipid droplet fusion and growth in hepatocellular carcinoma (Wu et al., 2014).

The role of membrane transport in metabolic downstream events is another aspect of the regulation of metabolism by Rab GTPases, which involve mechanistic/mammalian target of rapamycin (mTOR) complex 1 (mTORC1) in downstream cascades. mTORC1 is a conserved serine/threonine kinase that regulates cell growth and metabolism in response to extracellular environmental stressors, such as aberrant nutrients, hormones, and energy (Nie et al., 2019). Rab32 knockdown increases lysosome biogenesis in hepatocellular carcinoma and cervical cancer and reduces the association of mTOR pathway proteins with lysosomes, which suggests that Rab32 regulates lysosomal mTORC1 trafficking and thereby controls metabolism (Drizyte-Miller et al., 2020). And Rab35 functions upstream of mTORC2. Oncogenic RAB35 transport PDGFR $\alpha$ to LAMP2positive endomembrane without the involvement of endosomes, suggesting its oncogenic potential (Wheeler et al., 2015). Besides, other Rab GTPases, such Rabla and Rab31 have also been reported to affect mTOR pathway in tumor, but it is unclear 
whether these effects are achieved by the membrane transport of Rab GTPases (Li et al., 2020a; Yang L. et al., 2020).

\section{Autophagy}

Autophagy is a crucial cellular homeostatic process induced by nutrient deprivation that promotes the recycling of molecules from unnecessary organelles and proteins that are then employed for the synthesis of functional organelles and proteins or the energy requirement during times of need (Mele et al., 2020). The formation of autophagosomes requires vesicular trafficking from the subcellular compartment to the site of autophagosome formation (Onorati et al., 2018). Therefore, a series of Rab GTPases play crucial roles in this process (Szatmari and Sass, 2014). For example, the Optineurin-Rabla complexes modulate autophagosome formation through regulating the translocation of LC3-EGFP to autophagosomes (Song et al., 2018). Both Rab2 and Rab7 are important to autophagosome maturation and autolysosome fusion, which indicates that Rab2 and Rab7 are key regulators in the delivery and degradation of autophagic cargos (Lorincz et al., 2017). In addition, RAB2 regulates the activity of ULK1 kinase, thus promotes autophagosome formation (Ding et al., 2019).

Indeed, the selective autophagic degradation of LDs is called lipophagy (Singh et al., 2009; Galluzzi et al., 2014). Thus, lipophagy represents the intersection of fat metabolism and autophagy. In this process, LDs bind autophagosomes and are moved into lysosomes, and Rab GTPases function in membrane trafficking. Rab10 could induce the recruitment of autophagosomes at the LD surface in hepatocellular carcinoma (Li et al., 2016, 2020b). In addition, Rab7 regulates the transport of multivesicular bodies and lysosomes to LDs in hepatocellular carcinoma (Schroeder et al., 2015).

Autophagy plays a dual role in cancer, depending on the cellular context and the extracellular environment of the tumor (Onorati et al., 2018). Notably, specific Rab GTPases also have dual functions in different types or subtypes of cancer. For example, in ovarian cancer cells, Rab25 knockdown increases autophagy levels and induces apoptosis. Rab25 promotes cancer in ovarian cancer by inhibiting autophagy (Liu et al., 2012). However, increased expression of Rab25 inhibited the FAK/Akt pathway, promoted autophagy, and inhibited the malignancy of renal carcinoma cells (Tringali et al., 2012). The above results suggest that autophagy may be involved in the mechanism of the dual roles of Rab GTPases in different tumors.

\section{Exosome Biogenesis and Secretion}

In our previous studies, we discussed the characteristics and mechanism of exosome secretion in cancer (Fan et al., 2018; Yang et al., 2019). Exosomes, nanoscale extracellular vesicles $40-100 \mathrm{~nm}$ in size, have attracted increasing attention because of their involvement in intracellular communication. Exosomes are derived from multivesicular bodies (MVBs). MVBs are late endosomal structures containing luminal vesicles. After the fusion of MVBs with the plasma membrane, exosomes are released.

The Rab GTPases have been observed to significantly promote exosome biogenesis and secretion. Reduced activity of RAB11 in
K562 cells is associated with reduced exosome release (Savina et al., 2002). Rab11 is also involved in the interaction between MVB and autophagosomes in K562 cells. Rab11 co-locates with LC3 during autophagy, which is associated with reduced exosome release. Further studies showed that Rab11 is involved in the docking of $\mathrm{Ca}^{2}+$ dependent MVB to the plasma membrane (Savina et al., 2005). Rab11-mediated secretion of exosomal TMPRSS2 promoted cell migration in breast cancer (Chi et al., 2020).

Although Rab11 is critical for exosome release in K562 cells and breast cancer cells, Rab11 does not affect exosome secretion in HeLa cells. In HeLa cells, the silencing of Rab27a and Rab27b reduces exosome secretion (Ostrowski et al., 2010). Rab27a regulates the size of MVB, while Rab27b controls their cell localization.

Invadopodia are an important site of Rab27a-regulated exosome secretion (Hoshino et al., 2013). So the secretion of Rab27a and exosomes is intrinsically related to the invasion of cancer cells. Rab27a knockdown in invasive cancer cell lines decreased exosome secretion, and Rab27a-mediated exosomes increased cell migration, chemotaxis, and invasion (Hendrix and De Wever, 2013; Chen et al., 2018; Guo et al., 2019). Furthermore, the transfer of mRNA into recipient cells was demonstrated to occur via exosome secretion by Rab27 regulation. Rab27mediated secretion of exosomal miR-23b was shown to be connected with invasion and metastasis in bladder carcinoma (Ostenfeld et al., 2014). Rab27b-regulated exosomal miR-34c-5p was demonstrated to be related to the senescence of leukemia stem cells (Peng et al., 2018). Although Rab35 are also reported, the function of Rab35-regulated exosomes in cancer remains unclear (Yang et al., 2019).

In addition to regulating tumor cells, Rab27a/b also participates in exosome exchange between different cells in the tumor microenvironment. Rab27a-induced exosomes derived from hypoxic colorectal cancer cells affected the growth and invasion of endothelial cells (Huang and Feng, 2017). Both Rab27a/b gene deletions in head and neck squamous cell carcinoma cells reduce exosomal-mediated innervation induction (Madeo et al., 2018). Similarly, exosomes derived from Rab27a-overexpressing cancer cells elicited the efficient induction of antitumor immunity ( $\mathrm{Li}$ et al., 2013). Rab27a/b also regulates macrophage exosome secretion (Binenbaum et al., 2018). Co-secretion of Rab27a-dependent exosomes contributes to the mobilization of tumor-promoting neutrophils and supports the growth of mouse breast tumors and their metastasis to the lung (Bobrie et al., 2012). It is worth noting that the role of Rab11 and Rab27a/b in exosome secretion is mainly based on in vitro experiments, and it is unclear whether Rab11 and Rab27a/b have similar functions in vivo.

\section{Drug Resistance}

Rab GTPases function in tumor drug resistance mainly from the following four aspects: (i) Rab7a affects drug efflux by the extracellular vesicle (Guerra et al., 2019). The exposure of cancer cells to hypoxia increased their exosome-medicated cisplatin efflux by upregulation of Rab27a (Dorayappan et al., 2018). These findings indicated the close relationship between 
Rab-regulated exosome secretion and tumor drug resistance. (ii) Rab8 can cooperate with transmembrane transport protein to promote drug resistance. Human epidermoid carcinoma resistant to cisplatin exhibits high Rab8 level. Rab8 colocalize with the TMEM205 and increase the secretion of cisplatin (Shen and Gottesman, 2012). (iii) Some Rab GTPases promote drug resistance by transporting membrane surface specific receptors. TNFRSF10B expression levels and cell surface levels are increased after treatment with certain chemotherapeutic agents, such as pemetrexet, which plays a key role in induction of apoptosis. Rab8 suppresses pemetrexet effect by regulating the TNFRSF10B transport to the cytoplasm (Wang et al., 2020). Besides, Rab13 affect the sensitization of gastric cancer to 5fluorouracil treatment by regulating the EGFR transport to the cell membrane (Chen et al., 2019). (iv) Rab5a and Rab21 function through recycling multidrug resistance (MDR) relative protein. ABCG2 (ATP-binding cassette transporter of subfamily G) is a half-transporter involved in drug efflux and the development of MDR in cancer cells (Pasello et al., 2020). Ectopically expressed ABCG2 was shown to be located in cell surface and function in drug efflux (Kapoor et al., 2018). Active Rab5a-Q79L in breast cancer cells reduced the expression of ABCG2 in the plasma membrane, decreasing ABCG2-mediated drug efflux. Moreover, a reduction in the Rab21 expression level promoted the surface localization of ABCG2. Rab5a and Rab21 function in ABCG2 surface localization and turnover and may be targets to overcome MDR (Yousaf and Ali, 2020).

\section{CLINICAL IMPLICATIONS OF RAB GTPases IN CANCER}

Many clinicopathological studies note that Rab GTPases function in several cancers (Goldenring, 2013). Here, we discuss the clinical significance of the Rab GTPases mentioned above (Table 2). Rabla expression is associated with tumor size, differentiation, lymph node metastasis, TNM stage and poor prognosis in patients with tongue squamous carcinoma, hepatocellular carcinomas and breast, prostate, lung, gastric, colorectal cancer (Cheng et al., 2019; Shao et al., 2019a,b). Thus, low Rab1b expression correlates with poor prognosis of breast cancer patients (Jiang et al., 2015). Rab2 is associated with poor prognosis of pancreatic and breast cancer patients (Luo et al., 2015; Jin et al., 2018). Rab5a is essential for the formation of vesicles that are specifically degraded by the extracellular matrix. Therefore, Rab5a was necessary to promote the local invasion and long-distance transmission of tumor cell lines, and this metastatic ability was associated with increased cellular motility. Therefore, high Rab5 expression correlates with poor prognosis in several cancers, including lung, liver, breast, ovarian cancer and glioma (Frittoli et al., 2014; Jian et al., 2020). Rab7 is an early-induced melanoma driver (Alonso-Curbelo et al., 2014). In addition, lung cancer and gastric cancer patients with high Rab7 expression show decreased survival rates (Liu et al., 2020; Xiao and Schmid, 2020). High Rab10 expression levels are associated with poor prognosis in HCC patients (Wang W. et al., 2017). In addition, colorectal carcinoma patients with high expression of both E-cadherin and Rab11 show a poor prognosis (Chung et al., 2016). Furthermore, Rab11a is associated with advanced TNM stage, positive nodal status and poor prognosis (Dong et al., 2017). Rab13 can induce chemotherapeutic resistance and indicates poor overall survival and progression-free survival (Chen et al., 2019). Rab21 is also highly expressed and associated with poor prognosis in pancreatic cancer (Anand et al., 2020). Low Rab37 protein expression levels in lung cancer indicate poor prognosis in patients with lung cancer at different stages and lymph node metastasis (Tsai et al., 2014). Additionally, Rab40b correlated with the prognosis, invasion classification, lymph node metastasis, and pathological stage (Li et al., 2015).

Sometimes, the role of Rab GTPases is different according to tumor type. The role of Rab GTPases is sometimes influenced by tumor type. Elevated expression of Rab27b is correlated with reduced survival times, lymph node metastasis and pathological grade (Hendrix et al., 2010; Zhang et al., 2012; Ostenfeld et al., 2014). Rab27a and Rab27b was associated with poor patient prognosis and advanced TNM stage (Dong et al., 2012). Although Rab27 seems oncogenic, it also functions as a cancer inhibitor. Rab27a is downregulated and correlated with poor patient prognosis, advanced TNM stage, distant metastasis, and local recurrence (Dong et al., 2015). Low expression of Rab27a and Rab27b is also correlated with poor prostate cancer patient prognosis (Worst et al., 2017). Another example is Rab25, which functions as a prognostic indicator for breast, ovarian, kidney and other cancers. However, low expression of Rab25 is correlated with a poor prognosis in colon cancer, suggesting its role in tumor inhibition (Nam et al., 2010). The significant conflict between the functions of Rab25 in promoting or inhibiting cancer progression in different cancer types might be due to the involvement CLIC3, which is needed for RAB25-regulated integrin transport (Wang S. et al., 2017).

\section{TARGETING RAB GTPases AS A CANCER THERAPEUTIC STRATEGY}

Rab GTPases are widely expressed and function as prognostic markers in various human cancers. Therefore, targeting Rab GTPases is undoubtedly a highly attractive strategy for drug discovery, and some efforts to target Rab GTPases have already been made. For example, ML282 can inhibit Rab7 with high efficacy (Hong et al., 2010). In addition, the use of competitive inhibitors that bind nucleotides is a feasible method to target Rab GTPases. Some small-molecule pan-GTPase inhibitors, such as CID1067700, were discovered by high-throughput screening experiments. CID1067700 could inhibit Rab7 in biochemical, cellular protein and downstream protein interaction assays, and cellular functional assays (Hong et al., 2015). Although CID1067700 and ML282 also inhibit other GTPases, pan-GTPase inhibitors could serve as templates from which to develop specific Rab GTPase inhibitors with drug potential.

Gene therapeutics targeting Rab GTPase have recently been utilized. Once the Rab GTPases that are crucial for progression were established, their expression could be affected by small interfering RNA as well as non-coding RNA (ncRNA), such 
TABLE 2 | Clinical implications of Rab GTPases in cancer.

\begin{tabular}{|c|c|c|c|c|}
\hline Rab GTPase & Cancer types & Expression & Clinical implications & References \\
\hline Rab1a & $\begin{array}{l}\text { Tongue } \\
\text { Breast } \\
\text { Prostate } \\
\text { Liver } \\
\text { Lung } \\
\text { Stomach } \\
\text { Colorectum }\end{array}$ & Increased & Poor prognosis & Cheng et al., 2019; Shao et al., 2019a,b \\
\hline Rab1b & Breast & Decreased & Good prognosis & Jiang et al., 2015 \\
\hline Rab2 & $\begin{array}{l}\text { Pancreas } \\
\text { Breast }\end{array}$ & Increased & Poor prognosis & Luo et al., 2015; Jin et al., 2018 \\
\hline Rab5a & $\begin{array}{l}\text { Lung } \\
\text { Liver } \\
\text { Breast } \\
\text { Ovarian } \\
\text { Glioma }\end{array}$ & Increased & Poor prognosis & Frittoli et al., 2014; Jian et al., 2020 \\
\hline Rab7 & $\begin{array}{l}\text { Melanoma } \\
\text { Lung } \\
\text { Stomach }\end{array}$ & Increased & Poor prognosis & $\begin{array}{l}\text { Alonso-Curbelo et al., 2014; Liu et al., } \\
\text { 2020; Xiao and Schmid, } 2020\end{array}$ \\
\hline Rab10 & Liver & Increased & Poor prognosis & Wang W. et al., 2017 \\
\hline Rab11Rab11a & $\begin{array}{l}\text { Colorectum } \\
\text { Lung }\end{array}$ & Increased & Poor prognosis & Chung et al., 2016; Dong et al., 2017 \\
\hline Rab13 & Stomach & Increased & Poor prognosis & Chen et al., 2019 \\
\hline Rab21 & Pancreas & Increased & Poor prognosis & Anand et al., 2020 \\
\hline \multirow[t]{2}{*}{ Rab25 } & $\begin{array}{l}\text { Breast } \\
\text { Ovarian } \\
\text { Kidney } \\
\text { Lung } \\
\text { Stomach } \\
\text { Liver } \\
\text { Bladder } \\
\text { Glioma } \\
\text { Prostate }\end{array}$ & Increased & Poor prognosis & Wang S. et al., 2017 \\
\hline & $\begin{array}{l}\text { Colorectum } \\
\text { Esophagus } \\
\text { Head and neck }\end{array}$ & Decreased & Poor prognosisGood prognosis & Nam et al., 2010; Wang S. et al., 2017 \\
\hline \multirow[t]{2}{*}{ Rab27a } & Liver & Increased & Poor prognosis & Guerra et al., 2019 \\
\hline & $\begin{array}{l}\text { Colorectum } \\
\text { Prostate }\end{array}$ & Decreased & Good prognosis & Dong et al., 2015; Worst et al., 2017 \\
\hline \multirow[t]{2}{*}{ Rab27b } & $\begin{array}{l}\text { Bladder } \\
\text { Breast } \\
\text { Liver }\end{array}$ & Increased & Poor prognosis & $\begin{array}{l}\text { Hendrix et al., 2010; Zhang et al., 2012; } \\
\text { Ostenfeld et al., 2014; Binenbaum et al., } \\
\text { 2018; Madeo et al., 2018; Guerra et al., } \\
2019\end{array}$ \\
\hline & Prostate & Decreased & Good prognosis & Worst et al., 2017 \\
\hline Rab37 & Lung & Increased & Poor prognosis & Tsai et al., 2014 \\
\hline Rab40b & Stomach & Increased & Poor prognosis & Li et al., 2015 \\
\hline
\end{tabular}

as long non-coding RNA (lncRNA) and microRNA (miRNA). For example, IncRNA HOTAIR could regulate Rab35 expression and localization, and thereby affect the exosome secretion in hepatocellular carcinoma (Yang et al., 2019). LINC00152 function as a sponge for miR-107 that targets Rab10 directly to promote tumor progression (Zhou and Huang, 2019). LncRNA SNHG3 also functions as a sponge in the regulation of miRNA-151a3p/Rab22a to modulate migration of osteosarcoma (Zheng et al., 2019). Although these studies have suggested that the suppression of oncogenic ncRNAs and overexpression of tumor-inhibited ncRNAs might serve as attractive methods for therapeutic schedule, improving ncRNAs delivery systems, ncRNAs stability and off-target effects remains a challenge. If we want to successfully achieve the translation of gene therapeutics from the bench to the bedside, these questions must be addressed.

\section{CONCLUSION}

Vesicle trafficking functions in invasion, migration, metabolism, autophagy, exosome secretion and drug resistance. Rab GTPases are central coordinators of membrane trafficking and act as critical checkpoints for vesicular transport. Furthermore, small alterations in Rab GTPases may cause significant changes in 
net trafficking. Because membrane recycling is tremendously dynamic, one cycle of protein recycling might take only a few minutes or even less time. Therefore, the abnormal expression of Rab GTPases can markedly affect vesicle trafficking. A small change in the expression or active state of Rab GTPases might cause large changes in cell processes over days and thereby might promote invasion, migration, metabolism, autophagy, exosome secretion and drug resistance. Overall, Rab GTPases are essential to cancer progression, and selective targeting of particular Rab GTPases might be an attractive therapeutic schedule. Strategies to change membrane trafficking through targeting Rab GTPases might help to provide therapeutic approaches to reverse tumor invasion, migration, metabolism, autophagy, exosome secretion and drug resistance.

\section{REFERENCES}

Alonso-Curbelo, D., Riveiro-Falkenbach, E., Perez-Guijarro, E., Cifdaloz, M., Karras, P., Osterloh, L., et al. (2014). RAB7 controls melanoma progression by exploiting a lineage-specific wiring of the endolysosomal pathway. Cancer Cell 26, 61-76. doi: 10.1016/j.ccr.2014.04.030

Anand, S., Khan, M. A., Khushman, M., Dasgupta, S., Singh, S., and Singh, A. P. (2020). Comprehensive analysis of expression, clinicopathological association and potential prognostic significance of RABs in pancreatic cancer. Int. J. Mol. Sci. 21:5580. doi: 10.3390/ijms21155580

Argenzio, E., Margadant, C., Leyton-Puig, D., Janssen, H., Jalink, K., Sonnenberg, A., et al. (2014). CLIC4 regulates cell adhesion and betal integrin trafficking. J. Cell Sci. 127(Pt 24), 5189-5203. doi: 10.1242/jcs.150623

Baba, T., Toth, D. J., Sengupta, N., Kim, Y. J., and Balla, T. (2019). Phosphatidylinositol 4,5-bisphosphate controls Rab7 and PLEKHM1 membrane cycling during autophagosome-lysosome fusion. EMBO J. 38:e100312. doi: 10.15252/embj.2018100312

Barbarin, A., and Frade, R. (2011). Procathepsin L secretion, which triggers tumour progression, is regulated by Rab4a in human melanoma cells. Biochem. J. 437, 97-107. doi: 10.1042/BJ20110361

Binenbaum, Y., Fridman, E., Yaari, Z., Milman, N., Schroeder, A., Ben David, G., et al. (2018). Transfer of miRNA in macrophage-derived exosomes induces drug resistance in pancreatic adenocarcinoma. Cancer Res. 78, 5287-5299. doi: 10.1158/0008-5472.CAN-18-0124

Bobrie, A., Krumeich, S., Reyal, F., Recchi, C., Moita, L. F., Seabra, M. C., et al. (2012). Rab27a supports exosome-dependent and -independent mechanisms that modify the tumor microenvironment and can promote tumor progression. Cancer Res. 72, 4920-4930. doi: 10.1158/0008-5472.CAN-12-0925

Bravo-Cordero, J. J., Marrero-Diaz, R., Megias, D., Genis, L., Garcia-Grande, A., Garcia, M. A., et al. (2007). MT1-MMP proinvasive activity is regulated by a novel Rab8-dependent exocytic pathway. EMBO J. 26, 1499-1510. doi: 10.1038/ sj.emboj.7601606

Burk, K., and Pasterkamp, R. J. (2019). Disrupted neuronal trafficking in amyotrophic lateral sclerosis. Acta Neuropathol. 137, 859-877. doi: 10.1007/ s00401-019-01964-7

Cai, T., Zhou, J., Zeng, Y., Du, W., Zhang, Y., Liu, T., et al. (2020). EVI5 is an oncogene that regulates the proliferation and metastasis of NSCLC cells. J. Exp. Clin. Cancer Res. 39:84. doi: 10.1186/s13046-020-01585-z

Castro-Castro, A., Marchesin, V., Monteiro, P., Lodillinsky, C., Rosse, C., and Chavrier, P. (2016). Cellular and molecular mechanisms of MT1-MMPdependent cancer cell invasion. Annu. Rev. Cell Dev. Biol. 32, 555-576. doi: 10.1146/annurev-cellbio-111315-125227

Caswell, P. T., Spence, H. J., Parsons, M., White, D. P., Clark, K., Cheng, K. W., et al. (2007). Rab25 associates with alpha5betal integrin to promote invasive migration in 3D microenvironments. Dev. Cell 13, 496-510. doi: 10.1016/j. devcel.2007.08.012

Ceresa, B. P., and Bahr, S. J. (2006). Rab7 activity affects epidermal growth factor:epidermal growth factor receptor degradation by regulating endocytic

\section{AUTHOR CONTRIBUTIONS}

HJ and YT designed the review article. LY, XP, BL, QF, SW, SY, XL, BW, MH, ST, and JL performed literature collection. $\mathrm{HL}$ conceived the study. All authors read and approved the final manuscript.

\section{FUNDING}

This research was supported by the National Natural Science Foundation of China (No. 81871983), the Natural Science Foundation of Liaoning Province (No. LQNK201719), and the Natural Science Foundation of Liaoning Province (No. 2020-BS-103).

trafficking from the late endosome. J. Biol. Chem. 281, 1099-1106. doi: 10.1074/ jbc.M504175200

Cernochova, R., Nekulova, M., and Holcakova, J. (2016). [Rab proteins, intracellular transport and cancer]. Klin Onkol. 29 Suppl 4(Suppl 4), 31-39.

Chen, L., Guo, P., He, Y., Chen, Z., Chen, L., Luo, Y., et al. (2018). HCC-derived exosomes elicit HCC progression and recurrence by epithelial-mesenchymal transition through MAPK/ERK signalling pathway. Cell Death Dis. 9:513. doi: 10.1038/s41419-018-0534-9

Chen, P., Chen, G., Wang, C., and Mao, C. (2019). RAB13 as a novel prognosis marker promotes proliferation and chemotherapeutic resistance in gastric cancer. Biochem. Biophys. Res. Commun. 519, 113-120. doi: 10.1016/j.bbrc. 2019.08.141

Cheng, K. W., Agarwal, R., Mitra, S., Lee, J. S., Carey, M., Gray, J. W., et al. (2012). Rab25 increases cellular ATP and glycogen stores protecting cancer cells from bioenergetic stress. EMBO Mol. Med. 4, 125-141. doi: 10.1002/emmm. 201100193

Cheng, Z., Shao, X., Xu, M., Wang, J., Kuai, X., Zhang, L., et al. (2019). Rab1A promotes proliferation and migration abilities via regulation of the HER2/AKTindependent mTOR/S6K1 pathway in colorectal cancer. Oncol. Rep. 41, 27172728. doi: 10.3892/or.2019.7071

Chi, M., Shi, X., Huo, X., Wu, X., Zhang, P., and Wang, G. (2020). Dexmedetomidine promotes breast cancer cell migration through Rab11mediated secretion of exosomal TMPRSS2. Ann. Transl. Med. 8:531. doi: 10. 21037/atm.2020.04.28

Cho, S. H., Kuo, I. Y., Lu, P. F., Tzeng, H. T., Lai, W. W., Su, W. C., et al. (2018). Rab37 mediates exocytosis of secreted frizzled-related protein 1 to inhibit Wnt signaling and thus suppress lung cancer stemness. Cell Death Dis. 9:868. doi: 10.1038/s41419-018-0915-0

Choi, J., Sung, J. Y., Lee, S., Yoo, J., Rongo, C., Kim, Y. N., et al. (2020). Rab8 and Rabin8-mediated tumor formation by hyperactivated EGFR signaling via FGFR signaling. Int. J. Mol. Sci. 21:7770. doi: 10.3390/ijms21207770

Chua, C. E., and Tang, B. L. (2015). Role of Rab GTPases and their interacting proteins in mediating metabolic signalling and regulation. Cell Mol. Life Sci. 72, 2289-2304. doi: 10.1007/s00018-015-1862-x

Chung, Y. C., Wei, W. C., Hung, C. N., Kuo, J. F., Hsu, C. P., Chang, K. J., et al. (2016). Rab11 collaborates E-cadherin to promote collective cell migration and indicates a poor prognosis in colorectal carcinoma. Eur. J. Clin. Invest 46, 1002-1011. doi: 10.1111/eci.12683

Cullis, D. N., Philip, B., Baleja, J. D., and Feig, L. A. (2002). Rab11-FIP2, an adaptor protein connecting cellular components involved in internalization and recycling of epidermal growth factor receptors. J. Biol. Chem. 277, 49158-49166. doi: 10.1074/jbc.M206316200

Ding, X., Jiang, X., Tian, R., Zhao, P., Li, L., Wang, X., et al. (2019). $\mathrm{RAB} 2$ regulates the formation of autophagosome and autolysosome in mammalian cells. Autophagy 15, 1774-1786. doi: 10.1080/15548627.2019.159 6478

Dolce, L. G., Ohbayashi, N., Silva, D., Ferrari, A. J. R., Pirolla, R. A. S., Schwarzer, A., et al. (2020). Unveiling the interaction between the molecular motor Myosin 
Vc and the small GTPase Rab3A. J. Proteomics 212, 103549. doi: 10.1016/j.jprot. 2019.103549

Dong, Q., Fu, L., Zhao, Y., Du, Y., Li, Q., Qiu, X., et al. (2017). Rab1la promotes proliferation and invasion through regulation of YAP in non-small cell lung cancer. Oncotarget 8, 27800-27811. doi: 10.18632/oncotarget.15359

Dong, W. W., Mou, Q., Chen, J., Cui, J. T., Li, W. M., and Xiao, W. H. (2012). Differential expression of Rab27A/B correlates with clinical outcome in hepatocellular carcinoma. World J. Gastroenterol. 18, 1806-1813. doi: 10.3748/ wjg.v18.i15.1806

Dong, W., Cui, J., Yang, J., Li, W., Wang, S., Wang, X., et al. (2015). Decreased expression of Rab27A and Rab27B correlates with metastasis and poor prognosis in colorectal cancer. Discov. Med. 20, 357-367.

Dong, W., Li, H., and Wu, X. (2019). Rab11-FIP2 suppressed tumor growth via regulation of PGK1 ubiquitination in non-small cell lung cancer. Biochem. Biophys. Res. Commun. 508, 60-65. doi: 10.1016/j.bbrc.2018.11.108

Dong, W., Qin, G., and Shen, R. (2016). Rab11-FIP2 promotes the metastasis of gastric cancer cells. Int. J. Cancer 138, 1680-1688. doi: 10.1002/ijc.29899

Dorayappan, K. D. P., Wanner, R., Wallbillich, J. J., Saini, U., Zingarelli, R., Suarez, A. A., et al. (2018). Hypoxia-induced exosomes contribute to a more aggressive and chemoresistant ovarian cancer phenotype: a novel mechanism linking STAT3/Rab proteins. Oncogene 37, 3806-3821. doi: 10.1038/s41388-018-01890

Drizyte-Miller, K., Chen, J., Cao, H., Schott, M. B., and McNiven, M. A. (2020). The small GTPase Rab32 resides on lysosomes to regulate mTORC1 signaling. J. Cell Sci. 133, jcs.236661. doi: 10.1242/jcs.236661

Fan, Q., Yang, L., Zhang, X., Peng, X., Wei, S., Su, D., et al. (2018). The emerging role of exosome-derived non-coding RNAs in cancer biology. Cancer Lett. 414, 107-115. doi: 10.1016/j.canlet.2017.10.040

Frittoli, E., Palamidessi, A., Marighetti, P., Confalonieri, S., Bianchi, F., Malinverno, C., et al. (2014). A RAB5/RAB4 recycling circuitry induces a proteolytic invasive program and promotes tumor dissemination. J. Cell Biol. 206, 307-328. doi: $10.1083 /$ jcb. 201403127

Galluzzi, L., Pietrocola, F., Levine, B., and Kroemer, G. (2014). Metabolic control of autophagy. Cell 159, 1263-1276. doi: 10.1016/j.cell.2014.11.006

Gkretsi, V., and Stylianopoulos, T. (2018). Cell adhesion and matrix stiffness: coordinating cancer cell invasion and metastasis. Front. Oncol. 8:145. doi: 10. 3389/fonc. 2018.00145

Goldenring, J. R. (2013). A central role for vesicle trafficking in epithelial neoplasia: intracellular highways to carcinogenesis. Nat. Rev. Cancer 13, 813-820. doi: $10.1038 / \mathrm{nrc} 3601$

Goud, B., Liu, S., and Storrie, B. (2018). Rab proteins as major determinants of the Golgi complex structure. Small GTPases 9, 66-75. doi: 10.1080/21541248.2017. 1384087

Guerra, F., Paiano, A., Migoni, D., Girolimetti, G., Perrone, A. M., De Iaco, P., et al. (2019). Modulation of RAB7A protein expression determines resistance to cisplatin through late endocytic pathway impairment and extracellular vesicular secretion. Cancers (Basel) 11:52. doi: 10.3390/cancers11010052

Gulbranson, D. R., Davis, E. M., Demmitt, B. A., Ouyang, Y., Ye, Y., Yu, H., et al. (2017). RABIF/MSS4 is a Rab-stabilizing holdase chaperone required for GLUT4 exocytosis. Proc. Natl. Acad. Sci. U.S.A. 114, e8224-e8233. doi: $10.1073 /$ pnas.1712176114

Guo, D., Lui, G. Y. L., Lai, S. L., Wilmott, J. S., Tikoo, S., Jackett, L. A., et al. (2019). RAB27A promotes melanoma cell invasion and metastasis via regulation of pro-invasive exosomes. Int. J. Cancer 144, 3070-3085. doi: 10.1002/ijc.32064

Halberg, N., Sengelaub, C. A., Navrazhina, K., Molina, H., Uryu, K., and Tavazoie, S. F. (2016). PITPNC1 recruits RAB1B to the golgi network to drive malignant secretion. Cancer Cell 29, 339-353. doi: 10.1016/j.ccell.2016.02.013

Hendrix, A., and De Wever, O. (2013). Rab27 GTPases distribute extracellular nanomaps for invasive growth and metastasis: implications for prognosis and treatment. Int. J. Mol. Sci. 14, 9883-9892. doi: 10.3390/ijms14059883

Hendrix, A., Maynard, D., Pauwels, P., Braems, G., Denys, H., Van den Broecke, R., et al. (2010). Effect of the secretory small GTPase Rab27B on breast cancer growth, invasion, and metastasis. J. Natl. Cancer Inst. 102, 866-880. doi: 10. 1093/jnci/djq153

Homma, Y., Hiragi, S., and Fukuda, M. (2020). Rab family of small GTPases: an updated view on their regulation and functions. FEBS J. 288, 36-55. doi: $10.1111 /$ febs. 15453
Hong, L., Guo, Y., BasuRay, S., Agola, J. O., Romero, E., Simpson, D. S., et al. (2015). A Pan-GTPase Inhibitor as a Molecular Probe. PLoS One 10:e0134317. doi: 10.1371/journal.pone.0134317

Hong, L., Simons, P., Waller, A., Strouse, J., Surviladze, Z., Ursu, O., et al. (2010). "A small molecule pan-inhibitor of Ras-superfamily GTPases with high efficacy towards Rab7," in Probe Reports from the NIH Molecular Libraries Program, (Rockville, MD: Bethesda. (MD)).

Hoshino, D., Kirkbride, K. C., Costello, K., Clark, E. S., Sinha, S., Grega-Larson, N., et al. (2013). Exosome secretion is enhanced by invadopodia and drives invasive behavior. Cell Rep. 5, 1159-1168. doi: 10.1016/j.celrep.2013.10.050

Howe, E. N., Burnette, M. D., Justice, M. E., Schnepp, P. M., Hedrick, V., Clancy, J. W., et al. (2020). Rab11b-mediated integrin recycling promotes brain metastatic adaptation and outgrowth. Nat. Commun. 11:3017. doi: 10.1038/ s41467-020-16832-2

Huang, Z., and Feng, Y. (2017). Exosomes derived from hypoxic colorectal cancer cells promote angiogenesis through Wnt4-Induced beta-catenin signaling in endothelial cells. Oncol. Res. 25, 651-661. doi: 10.3727/ 096504016 X14752792816791

Jackson, C. L. (2019). Lipid droplet biogenesis. Curr. Opin. Cell Biol. 59, 88-96. doi: 10.1016/j.ceb.2019.03.018

Jacob, A., Jing, J., Lee, J., Schedin, P., Gilbert, S. M., Peden, A. A., et al. (2013). Rab40b regulates trafficking of MMP2 and MMP9 during invadopodia formation and invasion of breast cancer cells. J. Cell Sci. 126(Pt 20), 4647-4658. doi: $10.1242 /$ jcs. 126573

Jeong, B. Y., Cho, K. H., Jeong, K. J., Park, Y. Y., Kim, J. M., Rha, S. Y., et al. (2018). Rab25 augments cancer cell invasiveness through a betal integrin/EGFR/VEGF-A/Snail signaling axis and expression of fascin. Exp. Mol. Med. 50:e435. doi: 10.1038/emm.2017.248

Jeong, H., Lim, K. M., Kim, K. H., Cho, Y., Lee, B., Knowles, B. C., et al. (2019). Loss of Rab25 promotes the development of skin squamous cell carcinoma through the dysregulation of integrin trafficking. J. Pathol. 249, 227-240. doi: 10.1002/path.5311

Jian, Z., Zhang, L., Jin, L., Lan, W., Zhang, W., and Gao, G. (2020). Rab5 regulates the proliferation, migration and invasion of glioma cells via cyclin E. Oncol. Lett. 20, 1055-1062. doi: 10.3892/ol.2020.11660

Jiang, H. L., Sun, H. F., Gao, S. P., Li, L. D., Hu, X., Wu, J., et al. (2015). Loss of RAB1B promotes triple-negative breast cancer metastasis by activating TGFbeta/SMAD signaling. Oncotarget 6, 16352-16365. doi: 10.18632/oncotarget. 3877

Jin, J., Wu, Y., Zhou, D., Sun, Q., and Wang, W. (2018). miR448 targets Rab2B and is pivotal in the suppression of pancreatic cancer. Oncol. Rep. 40, 1379-1389. doi: 10.3892/or.2018.6562

Kajiho, H., Kajiho, Y., and Scita, G. (2018). Harnessing membrane trafficking to promote cancer spreading and invasion: the case of RAB2A. Small GTPases 9, 304-309. doi: 10.1080/21541248.2016.1223990

Kajiho, H., Kajiho, Y., Frittoli, E., Confalonieri, S., Bertalot, G., Viale, G., et al. (2016). RAB2A controls MT1-MMP endocytic and E-cadherin polarized Golgi trafficking to promote invasive breast cancer programs. EMBO Rep. 17, 10611080. doi: 10.15252/embr.201642032

Kapoor, P., Horsey, A. J., Cox, M. H., and Kerr, I. D. (2018). ABCG2: does resolving its structure elucidate the mechanism? Biochem. Soc. Trans. 46, 1485-1494. doi: 10.1042/BST20180145

LaFlamme, S. E., Mathew-Steiner, S., Singh, N., Colello-Borges, D., and Nieves, B. (2018). Integrin and microtubule crosstalk in the regulation of cellular processes. Cell Mol. Life Sci. 75, 4177-4185. doi: 10.1007/s00018-018-2913-x

Lamber, E. P., Siedenburg, A. C., and Barr, F. A. (2019). Rab regulation by GEFs and GAPs during membrane traffic. Curr. Opin. Cell Biol. 59, 34-39. doi: 10. 1016/j.ceb.2019.03.004

Li, G., and Marlin, M. C. (2015). Rab family of GTPases. Methods Mol. Biol. 1298, 1-15. doi: 10.1007/978-1-4939-2569-8_1

Li, W., Mu, D., Tian, F., Hu, Y., Jiang, T., Han, Y., et al. (2013). Exosomes derived from Rab27aoverexpressing tumor cells elicit efficient induction of antitumor immunity. Mol. Med. Rep. 8, 1876-1882. doi: 10.3892/mmr.2013.1738

Li, Y., Jia, Q., Wang, Y., Li, F., Jia, Z., and Wan, Y. (2015). Rab40b upregulation correlates with the prognosis of gastric cancer by promoting migration, invasion, and metastasis. Med. Oncol. 32:126. doi: 10.1007/s12032-0150562-6 
Li, Y., Yang, X., Du, X., Lei, Y., He, Q., Hong, X., et al. (2018). RAB37 hypermethylation regulates metastasis and resistance to docetaxel-based induction chemotherapy in nasopharyngeal carcinoma. Clin. Cancer Res. 24, 6495-6508. doi: 10.1158/1078-0432.CCR-18-0532

Li, Z., Li, Y., Jia, Y., Ding, B., and Yu, J. (2020a). Rab1A knockdown represses proliferation and promotes apoptosis in gastric cancer cells by inhibition of mTOR/p70S6K pathway. Arch. Biochem. Biophys. 685:108352. doi: 10.1016/j. abb. 2020.108352

Li, Z., Schulze, R. J., Weller, S. G., Krueger, E. W., Schott, M. B., Zhang, X., et al. (2016). A novel Rab10-EHBP1-EHD2 complex essential for the autophagic engulfment of lipid droplets. Sci. Adv. 2:e1601470. doi: 10.1126/sciadv.160 1470

Li, Z., Weller, S. G., Drizyte-Miller, K., Chen, J., Krueger, E. W., Mehall, B., et al. (2020b). Maturation of lipophagic organelles in hepatocytes is dependent upon a Rab10/Dynamin-2 complex. Hepatology 72, 486-502. doi: 10.1002/hep.31059

Liu, H., Xu, J., Yao, Q., Zhang, Z., Guo, Q., and Lin, J. (2020). Rab7 is associated with poor prognosis of gastric cancer and promotes proliferation, invasion, and migration of gastric cancer cells. Med. Sci. Monit. 26:e922217. doi: 10.12659/ MSM.922217

Liu, Y., Tao, X., Jia, L., Cheng, K. W., Lu, Y., Yu, Y., et al. (2012). Knockdown of RAB25 promotes autophagy and inhibits cell growth in ovarian cancer cells. Mol. Med. Rep. 6, 1006-1012. doi: 10.3892/mmr.2012.1052

Lorincz, P., Toth, S., Benko, P., Lakatos, Z., Boda, A., Glatz, G., et al. (2017). Rab2 promotes autophagic and endocytic lysosomal degradation. J. Cell Biol. 216, 1937-1947. doi: $10.1083 /$ jcb.201611027

Luo, M. L., Gong, C., Chen, C. H., Hu, H., Huang, P., Zheng, M., et al. (2015). The Rab2A GTPase promotes breast cancer stem cells and tumorigenesis via Erk signaling activation. Cell Rep. 11, 111-124. doi: 10.1016/j.celrep.2015.03.002

Madeo, M., Colbert, P. L., Vermeer, D. W., Lucido, C. T., Cain, J. T., Vichaya, E. G., et al. (2018). Cancer exosomes induce tumor innervation. Nat. Commun. 9:4284. doi: 10.1038/s41467-018-06640-0

Malia, P. C., Numrich, J., Nishimura, T., Gonzalez Montoro, A., Stefan, C. J., and Ungermann, C. (2018). Control of vacuole membrane homeostasis by a resident PI-3,5-kinase inhibitor. Proc. Natl. Acad. Sci. U.S.A. 115, 4684-4689. doi: 10.1073/pnas.1722517115

Mele, L., Del Vecchio, V., Liccardo, D., Prisco, C., Schwerdtfeger, M., Robinson, N., et al. (2020). The role of autophagy in resistance to targeted therapies. Cancer Treat Rev. 88:102043. doi: 10.1016/j.ctrv.2020.102043

Minamino, N., and Ueda, T. (2019). RAB GTPases and their effectors in plant endosomal transport. Curr. Opin. Plant Biol. 52, 61-68. doi: 10.1016/j.pbi.2019. 07.007

Müller, M. P., and Goody, R. S. (2018). Molecular control of Rab activity by GEFs, GAPs and GDI. Small GTPases 9, 5-21. doi: 10.1080/21541248.2016.1276999

Nam, K. T., Lee, H. J., Smith, J. J., Lapierre, L. A., Kamath, V. P., Chen, X., et al. (2010). Loss of Rab25 promotes the development of intestinal neoplasia in mice and is associated with human colorectal adenocarcinomas. J. Clin. Invest. 120, 840-849. doi: 10.1172/JCI40728

Nie, Y., Yu, S., Li, Q., Nirala, N. K., Amcheslavsky, A., Edwards, Y. J. K., et al. (2019). Oncogenic pathways and loss of the Rab11 GTPase Synergize To alter metabolism in Drosophila. Genetics 212, 1227-1239. doi: 10.1534/genetics.119. 302137

Novick, P. (2016). Regulation of membrane traffic by Rab GEF and GAP cascades. Small GTPases 7, 252-256. doi: 10.1080/21541248.2016.1213781

Onorati, A. V., Dyczynski, M., Ojha, R., and Amaravadi, R. K. (2018). Targeting autophagy in cancer. Cancer 124, 3307-3318. doi: 10.1002/cncr. 31335

Ostenfeld, M. S., Jeppesen, D. K., Laurberg, J. R., Boysen, A. T., Bramsen, J. B., Primdal-Bengtson, B., et al. (2014). Cellular disposal of miR23b by RAB27-dependent exosome release is linked to acquisition of metastatic properties. Cancer Res. 74, 5758-5771. doi: 10.1158/0008-5472.CAN-133512

Ostrowski, M., Carmo, N. B., Krumeich, S., Fanget, I., Raposo, G., Savina, A., et al. (2010). Rab27a and Rab27b control different steps of the exosome secretion pathway. Nat. Cell Biol. 12, 19-30. doi: 10.1038/ncb2000

Pasello, M., Giudice, A. M., and Scotlandi, K. (2020). The ABC subfamily A transporters: multifaceted players with incipient potentialities in cancer. Semin. Cancer Biol. 60, 57-71. doi: 10.1016/j.semcancer.2019.10.004
Pellinen, T., Arjonen, A., Vuoriluoto, K., Kallio, K., Fransen, J. A., and Ivaska, J. (2006). Small GTPase Rab21 regulates cell adhesion and controls endosomal traffic of beta1-integrins. J. Cell Biol. 173, 767-780. doi: 10.1083/jcb.200509019

Peng, D., Wang, H., Li, L., Ma, X., Chen, Y., Zhou, H., et al. (2018). miR-34c$5 p$ promotes eradication of acute myeloid leukemia stem cells by inducing senescence through selective RAB27B targeting to inhibit exosome shedding. Leukemia 32, 1180-1188. doi: 10.1038/s41375-018-0015-2

Porther, N., and Barbieri, M. A. (2015). The role of endocytic Rab GTPases in regulation of growth factor signaling and the migration and invasion of tumor cells. Small GTPases 6, 135-144. doi: 10.1080/21541248.2015.1050152

Prasad, N. R., Muthusamy, G., Shanmugam, M., and Ambudkar, S. V. (2016). South Asian Medicinal Compounds as Modulators of Resistance to Chemotherapy and Radiotherapy. Cancers (Basel) 8:32. doi: 10.3390/cancers8030032

Sahgal, P., Alanko, J., Icha, J., Paatero, I., Hamidi, H., Arjonen, A., et al. (2019). GGA2 and RAB13 promote activity-dependent beta1-integrin recycling. J. Cell Sci. 132:jcs.233387. doi: 10.1242/jcs.233387

Savina, A., Fader, C. M., Damiani, M. T., and Colombo, M. I. (2005). Rab11 promotes docking and fusion of multivesicular bodies in a calciumdependent manner. Traffic 6, 131-143. doi: 10.1111/j.1600-0854.2004. 00257.x

Savina, A., Vidal, M., and Colombo, M. I. (2002). The exosome pathway in K562 cells is regulated by Rab11. J. Cell Sci. 115(Pt 12), 2505-2515.

Schroeder, B., Schulze, R. J., Weller, S. G., Sletten, A. C., Casey, C. A., and McNiven, M. A. (2015). The small GTPase Rab7 as a central regulator of hepatocellular lipophagy. Hepatology 61, 1896-1907. doi: 10.1002/hep.27667

Shao, X., Cheng, Z., Xu, M., Mao, J., Wang, J., and Zhou, C. (2019a). Prognosis, significance and positive correlation of Rab1A and p-S6K/Glil expression in gastric cancer. Anticancer. Agents Med. Chem. 19, 1359-1367. doi: 10.2174/ 1871520619666190416110851

Shao, X., Cheng, Z., Xu, M., Tan, Z., Gao, L., Wang, J., et al. (2019b). Pooled analysis of prognostic value and clinical significance of Rab1A expression in human solid tumors. Medicine (Baltimore) 98:e18370. doi: 10.1097/md. 0000000000018370

Shen, D. W., and Gottesman, M. M. (2012). RAB8 enhances TMEM205-mediated cisplatin resistance. Pharm. Res. 29, 643-650. doi: 10.1007/s11095-011-0562-y

Singh, R., Kaushik, S., Wang, Y., Xiang, Y., Novak, I., Komatsu, M., et al. (2009). Autophagy regulates lipid metabolism. Nature 458, 1131-1135. doi: 10.1038/ nature 07976

Song, G. J., Jeon, H., Seo, M., Jo, M., and Suk, K. (2018). Interaction between optineurin and Rabla regulates autophagosome formation in neuroblastoma cells. J. Neurosci. Res. 96, 407-415. doi: 10.1002/jnr.24143

Stallaert, W., Bruggemann, Y., Sabet, O., Baak, L., Gattiglio, M., and Bastiaens, P. I. H. (2018). Contact inhibitory Eph signaling suppresses EGF-promoted cell migration by decoupling EGFR activity from vesicular recycling. Sci. Signal. 11:eaat0114. doi: 10.1126/scisignal.aat0114

Steffan, J. J., Dykes, S. S., Coleman, D. T., Adams, L. K., Rogers, D., Carroll, J. L., et al. (2014). Supporting a role for the GTPase Rab7 in prostate cancer progression. PLoS One 9:e87882. doi: 10.1371/journal.pone.0087882

Stenmark, H. (2009). Rab GTPases as coordinators of vesicle traffic. Nat. Rev. Mol. Cell Biol. 10, 513-525. doi: 10.1038/nrm2728

Szatmari, Z., and Sass, M. (2014). The autophagic roles of Rab small GTPases and their upstream regulators: a review. Autophagy 10, 1154-1166. doi: 10.4161/ auto. 29395

Tang, D., Sheng, J., Xu, L., Zhan, X., Liu, J., Jiang, H., et al. (2020). Cryo-EM structure of C9ORF72-SMCR8-WDR41 reveals the role as a GAP for Rab8a and Rab11a. Proc. Natl. Acad. Sci. U.S.A. 117, 9876-9883. doi: 10.1073/pnas. 2002110117

Tang, L., Peng, C., Zhu, S. S., Zhou, Z., Liu, H., Cheng, Q., et al. (2020). Tre2Bub2-Cdc16 family proteins based nomogram serve as a promising prognosis predicting model for melanoma. Front. Oncol. 10:579625. doi: 10.3389/fonc. 2020.579625

Tringali, C., Lupo, B., Silvestri, I., Papini, N., Anastasia, L., Tettamanti, G., et al. (2012). The plasma membrane sialidase NEU3 regulates the malignancy of renal carcinoma cells by controlling betal integrin internalization and recycling. J. Biol. Chem. 287, 42835-42845. doi: 10.1074/jbc.M112.407718

Tsai, C. H., Cheng, H. C., Wang, Y. S., Lin, P., Jen, J., Kuo, I. Y., et al. (2014). Small GTPase Rab37 targets tissue inhibitor of metalloproteinase 1 for exocytosis 
and thus suppresses tumour metastasis. Nat. Commun. 5:4804. doi: 10.1038/ ncomms5804

Wang, J., Zhou, P., Wang, X., Yu, Y., Zhu, G., Zheng, L., et al. (2019). Rab25 promotes erlotinib resistance by activating the beta1 integrin/AKT/beta-catenin pathway in NSCLC. Cell Prolif. 52:e12592. doi: 10.1111/cpr.12592

Wang, S., Hu, C., Wu, F., and He, S. (2017). Rab25 GTPase: functional roles in cancer. Oncotarget 8, 64591-64599. doi: 10.18632/oncotarget. 19571

Wang, W., Jia, W. D., Hu, B., and Pan, Y. Y. (2017). RAB10 overexpression promotes tumor growth and indicates poor prognosis of hepatocellular carcinoma. Oncotarget 8, 26434-26447. doi: 10.18632/oncotarget.15507

Wang, Y. S., Tzeng, H. T., Tsai, C. H., Cheng, H. C., Lai, W. W., Liu, H. S., et al. (2018). VAMP8, a vesicle-SNARE required for RAB37-mediated exocytosis, possesses a tumor metastasis suppressor function. Cancer Lett. 437, 79-88. doi: 10.1016/j.canlet.2018.08.023

Wang, Y., Guo, S., Li, D., Tang, Y., Li, L., Su, L., et al. (2020). YIPF2 promotes chemotherapeutic agent-mediated apoptosis via enhancing TNFRSF10B recycling to plasma membrane in non-small cell lung cancer cells. Cell Death Dis. 11:242. doi: 10.1038/s41419-020-2436-x

Wheeler, D. B., Zoncu, R., Root, D. E., Sabatini, D. M., and Sawyers, C. L. (2015). Identification of an oncogenic RAB protein. Science 350, 211-217. doi: 10.1126/ science.aaa4903

Worst, T. S., Meyer, Y., Gottschalt, M., Weis, C. A., von Hardenberg, J., Frank, C., et al. (2017). RAB27A, RAB27B and VPS36 are downregulated in advanced prostate cancer and show functional relevance in prostate cancer cells. Int. J. Oncol. 50, 920-932. doi: 10.3892/ijo.2017.3872

Wu, L., Xu, D., Zhou, L., Xie, B., Yu, L., Yang, H., et al. (2014). Rab8a-AS160MSS4 regulatory circuit controls lipid droplet fusion and growth. Dev. Cell 30, 378-393. doi: 10.1016/j.devcel.2014.07.005

Xiao, G. Y., and Schmid, S. L. (2020). FCHSD2 controls oncogenic ERK1/2 signaling outcome by regulating endocytic trafficking. PLoS Biol. 18:e3000778. doi: 10.1371/journal.pbio.3000778

Yamori, Y., Horie, R., Nara, Y., Ikeda, K., Kihara, M., Ooshima, A., et al. (1981). Genetics of hypertensive diseases - experimental studies on pathogenesis, detection of predisposition and prevention. Adv. Nephrol. Necker Hosp. 10, 51-74.

Yang, L., Peng, X., Li, Y., Zhang, X., Ma, Y., Wu, C., et al. (2019). Long non-coding RNA HOTAIR promotes exosome secretion by regulating RAB35 and SNAP23 in hepatocellular carcinoma. Mol. Cancer 18:78. doi: 10.1186/s12943-019-09906

Yang, L., Tian, X., Chen, X., Lin, X., Tang, C., Gao, Y., et al. (2020). Upregulation of Rab31 is associated with poor prognosis and promotes colorectal carcinoma proliferation via the mTOR/p70S6K/Cyclin D1 signalling pathway. Life Sci. 257:118126. doi: $10.1016 /$ j.lfs. 2020.118126
Yang, R., Liu, G., Han, L., Qiu, Y., Wang, L., and Wang, M. (2021). MiR-365a-3pmediated regulation of HELLS/GLUT1 Axis suppresses aerobic glycolysis and gastric cancer growth. Front. Oncol. 11:616390. doi: 10.3389/fonc.2021.616390

Yang, T., Zhiheng, H., Zhanhuai, W., Qian, X., Yue, L., Xiaoxu, G., et al. (2020). Increased RAB31 expression in cancer-associated fibroblasts promotes colon cancer progression through HGF-MET signaling. Front. Oncol. 10:1747. doi: 10.3389/fonc.2020.01747

Yang, Y., Yang, Y., Yang, J., Zhao, X., and Wei, X. (2020). Tumor Microenvironment in Ovarian Cancer: Function and Therapeutic Strategy. Front. Cell Dev. Biol. 8:758. doi: 10.3389/fcell.2020.00758

Yoon, S. O., Shin, S., and Mercurio, A. M. (2005). Hypoxia stimulates carcinoma invasion by stabilizing microtubules and promoting the Rab11 trafficking of the alpha6beta4 integrin. Cancer Res. 65, 2761-2769. doi: 10.1158/0008-5472.CAN04-4122

Yousaf, M., and Ali, M. (2020). Modulation of ABCG2 surface expression by Rab5 and Rab21 to overcome multidrug resistance in cancer cells. Xenobiotica 50, 988-996. doi: 10.1080/00498254.2020.1716107

Yuan, Z., and Wei, W. (2021). RAB5A promotes the formation of filopodia in pancreatic cancer cells via the activation of cdc42 and betal-integrin. Biochem. Biophys. Res. Commun. 535, 54-59. doi: 10.1016/j.bbrc.2020.12.022

Zhang, J. X., Huang, X. X., Cai, M. B., Tong, Z. T., Chen, J. W., Qian, D., et al. (2012). Overexpression of the secretory small GTPase Rab27B in human breast cancer correlates closely with lymph node metastasis and predicts poor prognosis. J. Transl. Med. 10:242. doi: 10.1186/1479-5876-10-242

Zheng, S., Jiang, F., Ge, D., Tang, J., Chen, H., Yang, J., et al. (2019). LncRNA SNHG3/miRNA-151a-3p/RAB22A axis regulates invasion and migration of osteosarcoma. Biomed. Pharmacother. 112:108695. doi: 10.1016/j.biopha.2019. 108695

Zhou, Z., and Huang, F. (2019). Long Non-Coding RNA LINC00152 regulates cell proliferation, migration and invasion in esophageal squamous cell carcinoma Via miR-107/Rab10 Axis. Onco. Targets Ther. 12, 8553-8567. doi: 10.2147/OTT. S221515

Conflict of Interest: The authors declare that the research was conducted in the absence of any commercial or financial relationships that could be construed as a potential conflict of interest.

Copyright (c) 2021 Jin, Tang, Yang, Peng, Li, Fan, Wei, Yang, Li, Wu, Huang, Tang, Liu and Li. This is an open-access article distributed under the terms of the Creative Commons Attribution License (CC BY). The use, distribution or reproduction in other forums is permitted, provided the original author(s) and the copyright owner(s) are credited and that the original publication in this journal is cited, in accordance with accepted academic practice. No use, distribution or reproduction is permitted which does not comply with these terms. 